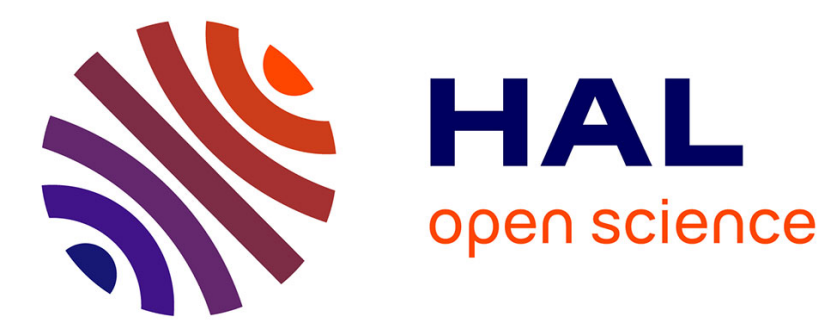

\title{
US deficit sustainability revisited: A multiple structural change approach
}

\author{
Oscar Bajo-Rubio, Vicente Esteve, Carmen Díaz-Roldán
}

\section{To cite this version:}

Oscar Bajo-Rubio, Vicente Esteve, Carmen Díaz-Roldán. US deficit sustainability revisited: A multiple structural change approach. Applied Economics, 2008, 40 (12), pp.1609-1613. 10.1080/00036840600843996 . hal-00582077

\section{HAL Id: hal-00582077 https://hal.science/hal-00582077}

Submitted on 1 Apr 2011

HAL is a multi-disciplinary open access archive for the deposit and dissemination of scientific research documents, whether they are published or not. The documents may come from teaching and research institutions in France or abroad, or from public or private research centers.
L'archive ouverte pluridisciplinaire HAL, est destinée au dépôt et à la diffusion de documents scientifiques de niveau recherche, publiés ou non, émanant des établissements d'enseignement et de recherche français ou étrangers, des laboratoires publics ou privés. 


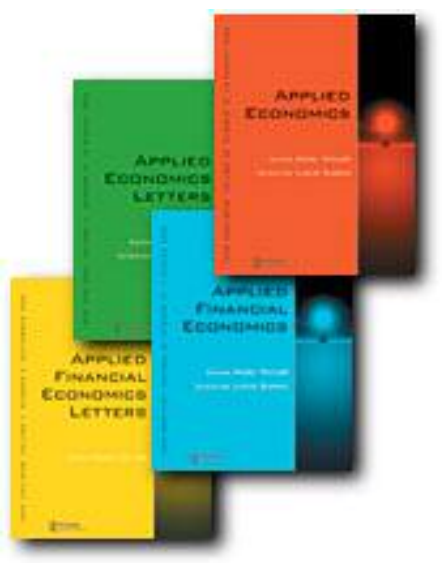

US deficit sustainability revisited: A multiple structural change approach

\begin{tabular}{|r|l|}
\hline Journal: & Applied Economics \\
\hline Manuscript ID: & APE-06-0105.R1 \\
\hline Journal Selection: & Applied Economics \\
\hline JEL Code: & $\begin{array}{l}\text { E62 - Fiscal Policy|Public Expenditures, Investment, and } \\
\text { Finance|Taxation < E6 - Macro Policy Formation, Macro Public } \\
\text { Economics, H62 - Deficit|Surplus < H6 - National Budget, Deficit, } \\
\text { and Debt < H - Public Economics }\end{array}$ \\
\hline Keywords: & Fiscal policy, Sustainability, US budget deficit \\
\hline
\end{tabular}

powered by ScholarOne

Manuscript Central ${ }^{\text {M }}$ 


\title{
US deficit sustainability revisited: A multiple structural change approach*
}

\author{
Oscar Bajo-Rubio \\ Universidad de Castilla-La Mancha \\ and Instituto de Estudios Fiscales, Spain \\ Carmen Díaz-Roldán \\ Universidad de Castilla-La Mancha, Spain \\ Vicente Esteve ${ }^{\dagger}$ \\ Universidad de Valencia, Spain
}

February 2006

\begin{abstract}
In this paper we re-examine the long-run sustainability of US budget deficits, using Bai and Perron's multiple structural change approach. While the deficit would have been weakly sustainable over the full sample (1947:1-2005:3), strong sustainability would appear only between 1982:1 and 1996:2.

Keywords: Fiscal policy; Sustainability; US budget deficit.

JEL classification: E62, H62.
\end{abstract}

\footnotetext{
${ }^{*}$ The authors acknowledge financial support from the Spanish Ministry of Education and Science, through the projects SEJ2005-08738-C02-01 (O. Bajo-Rubio and C. Díaz-Roldán) and SEJ2005-01163 (V. Esteve).

${ }^{\dagger}$ Corresponding author: Departamento de Economia Aplicada II, Universidad de Valencia, Avda. dels Tarongers, s/n, 46022 Valencia, Spain. Fax: +34-96-3828354. e-mail: vicente.esteve@uv.es.
} 


\section{Introduction}

US government finances have experienced a remarkable turnaround in recent years. Large budget deficits in the 1980s and early 1990s led to a substantial amount of empirical work aimed to examining their long-run sustainability. However, later on, the record surpluses in the late 1990s and early 2000s turned into record deficits after 2002, with budget projections showing large federal deficits over the next decade. As a result, the US general government deficit is now among the highest in the OECD, and its sustainability has become again a highly relevant issue.

When analyzing the sustainability of budget deficits, the traditional approach has consisted of testing whether the government's intertemporal budget constraint (IBC) holds, that is, whether the current market value of debt equals the discounted sum of expected future surpluses. However, empirical tests on sustainability are largely inconclusive due to differences in the econometric methodology, the particular specification of the transversality condition, and the sample period used.

Several procedures to test for the IBC have been proposed in the literature, focusing either on the univariate properties of the government's deficit and debt (e.g., Hamilton and Flavin, 1986; Wilcox, 1989), or on the presence of a long-run cointegration relationship between government revenues and expenditures (e.g., Trehan and Walsh, 1988, 1991; Haug, 1991). Furthermore, the eventual occurrence of a structural break in the cointegrating relationship has been examined in, e.g., Quintos (1995) and Martin (2000). Overall, the results of these and other studies suggest that the US deficit would have undergone a shift in recent times, with the deficit being either unsustainable or only weakly sustainable in the post-break period.

In this paper we re-examine the sustainability of US budget deficits, using a new approach developed by Bai and Perron $(1998,2003 \mathrm{a})$. This procedure allows to test endogenously for the presence of multiple structural changes in an estimated relationship, and has a number of advantages over previous approaches. In particular, the underlying assumptions are less restrictive, confidence intervals for the break dates can be calculated, the data and errors are allowed to follow different distributions across segments, and the sequential method used in the application can allow for the presence of serial correlation in the errors and heterogeneous variances across segments; see Bai and Perron (2006) for details. As a further contribution, as compared with previous studies where the sample ends at the early 1990s, our period of analysis extends to 2005, including the most recent developments in the evolution of the US budget deficit.

The rest of the paper is organized as follows. A brief description of the underlying theoretical framework is provided in section 2, the methodology and empirical results are presented in section 3 , and the main conclusions are summarized in section 4 . 


\section{Theoretical framework}

Assuming that budget deficits are financed using bonds of one-period maturity, in any single period a government faces the following budget constraint:

$$
\Delta B_{t}=G_{t}-R_{t}
$$

where $B_{t}, G_{t}$, and $R_{t}$ denote, respectively, the real market value of government debt, real government expenditure inclusive of interest payments, and real tax revenues. The real interest rate is assumed to be stationary around a mean $r$ so that, defining $E X P_{t}$ as $G_{t}-r B_{t-1}$, the constraint (1) can be rewritten as:

$$
B_{t}=E X P_{t}-R_{t}+(1+r) B_{t-1}
$$

Since (2) holds every period, solving for $B_{t}$ and iterating forward over an infinite horizon yields the IBC:

$$
B_{t}=\sum_{j=0}^{\infty}\left(\frac{1}{1+r}\right)^{j+1}\left(R_{t+j+1}-E X P_{t+j+1}\right)+\lim _{j \rightarrow \infty}\left(\frac{1}{1+r}\right)^{j+1} B_{t+j+1}
$$

If we denote as $E_{t}$ the expectations operator, conditional on information at time $t$, fiscal sustainability involves:

$$
\lim _{j \rightarrow \infty}\left(\frac{1}{1+r}\right)^{j+1} E_{t} B_{t+j+1}=0
$$

i.e., the government must run future budget surpluses equal, in present-value terms, to the current value of its outstanding debt; in other words, the budget deficit would be sustainable if and only if the stock of debt is expected to grow no faster on average than $r$ (taken as a proxy of the growth rate of the economy).

The cointegration framework for testing the IBC would follow once first differences are taken in (3):

$\Delta B_{t}=\sum_{j=0}^{\infty}\left(\frac{1}{1+r}\right)^{j+1}\left(\Delta R_{t+j+1}-\Delta E X P_{t+j+1}\right)+\lim _{j \rightarrow \infty}\left(\frac{1}{1+r}\right)^{j+1} \Delta B_{t+j+1}$

so that sustainability would require:

$$
\lim _{j \rightarrow \infty}\left(\frac{1}{1+r}\right)^{j+1} E_{t} \Delta B_{t+j+1}=0
$$

Under a no-Ponzi scheme rule, the right-hand side of equation (5) will be stationary as long as government revenues and expenditures, and the stock of public debt, are all stationary in first differences. In order to test for condition (6), the usual procedure consists of testing for the stationarity of $\Delta B_{t}=G_{t}-R_{t}$, 
provided that both $G_{t}$ and $R_{t}$ are I(1), with a cointegration relationship $(1,-1)$, in a regression model of the form:

$$
R_{t}=\alpha+\beta G_{t}+\varepsilon_{t}
$$

and then testing the linear restriction $\beta=1$. In particular, Quintos (1995) shows that:

(i) The fiscal deficit would be strongly sustainable if and only if $R_{t}$ and $G_{t}$ are cointegrated and $\beta=1$.

(ii) The fiscal deficit would be only weakly sustainable if $R_{t}$ and $G_{t}$ are cointegrated and $0<\beta<1$.

(iii) The fiscal deficit would be unsustainable if $\beta \leq 0$.

\section{Methodology and empirical results}

In this section we provide a test of the sustainability of the US budget deficit, over the period 1947:1 to 2005:3. The data on federal government revenues and expenditures, inclusive of interest paid on debt, are taken from the National Income Product Accounts (NIPA, Table 3.1), and real values are calculated using the GDP deflator (NIPA, Table 1.1.4).

As a first step of the analysis, we test for the order of integration of the series using the tests of $\mathrm{Ng}$ and Perron (2001). The results are shown in Table 1 , and the null hypothesis of non stationarity cannot be rejected, independently of the test, for the two series in levels; at the same time that the presence of two unit roots is clearly rejected at the $1 \%$ significance level. Accordingly, both series would be concluded to be I(1).

Next, we perform a cointegration analysis of equation (7) over the whole sample, with no breaks included. The estimation is made using the method of Dynamic Ordinary Least Squares (DOLS) of Stock and Watson (1993). So, we first estimate a long-run dynamic equation including leads and lags of the explanatory variables in equation (7):

$$
R_{t}=\alpha+\beta G_{t}+\sum_{j=-q}^{q} \gamma_{j} \Delta G_{t-j}+v_{t}
$$

where $v_{t}$ is an error term, and then perform Shin's (1994) test from the calculation of $C_{\mu}$, a LM statistic from the DOLS residuals, which tests for deterministic cointegration (i.e., when no trend is present in the regression).

The results in the first column of Table 2 show that the null of deterministic cointegration between $R_{t}$ and $G_{t}$ is not rejected at the $1 \%$ level of significance, and the estimated value for $\beta$ is 0.93 , significantly different from zero at the $1 \%$ level. But this estimate would be significantly different from one at the $1 \%$ level, according to a Wald test on the null hypothesis $\hat{\beta}=1$ against the alternative $\hat{\beta}<1$, distributed as a $\chi_{1}^{2}$ and denoted by $W_{D O L S}$ in Table 2. Accordingly, since $R_{t}$ and $G_{t}$ would be cointegrated and $0<\hat{\beta}<1$, the US fiscal deficit would have been only weakly sustainable over the full sample 1947:1-2005:3. 
This would confirm, over a more extended period, previous results by Quintos (1995) and Martin (2000) for the same sample ending at 1992.3.

But the main objective of this section is estimating equation (7) through a multiple endogenous break model. Hence, we now proceed to test for multiple breaks at unknown dates in equation (7), making use of the approach of Bai and Perron (1998, 2003a), who suggest several statistics in order to identify the break points:

- The $\sup F_{T}(k)$ test, i.e., a sup $F$-type test of the null hypothesis of no structural break versus the alternative of a fixed (arbitrary) number of breaks $k$.

- Two maximum tests of the null hypothesis of no structural break versus the alternative of an unknown number of breaks given some upper bound, i.e., $U D \max$ test, an equal weighted version, and $W D \max$ test, with weights that depend on the number of regressors and the significance level of the test.

- The $\sup F_{T}(l+1 \mid l)$ test, i.e., a sequential test of the null hypothesis of $l$ breaks versus the alternative of $l+1$ breaks.

The results of applying the Bai-Perron tests to the relationship between $R_{t}$ and $G_{t}$, allowing up to five breaks, are shown in Table 3. Both the $U D$ max and $W D$ max tests are highly significant, which implies that at least one break is present. Next, all the $\sup F_{T}(k)$ tests are significant, with $k$ running between 1 and 5 , so that at least one break would be present in this relationship. In turn, the $\sup F_{T}(l+1 \mid l)$ test is not significant for any $l \geq 3$, so the sequential procedure selects three breaks. Hence, the results of the Bai-Perron tests would suggest a model of four regimes, with the dates of the breaks estimated at 1955:3, 1982:1, and 1996:3; their confidence intervals are shown in Table 3.

Finally, we proceed to estimate the cointegration equation (8) for the four sub-samples, and the results are shown in the last four columns of Table 2. As can be seen, in the first and second regimes (1947:1-1955:2 and 1955:3-1981:4) the null of deterministic cointegration is not rejected at the $1 \%$ level, and the restriction on the estimate of $\beta$ being equal to one is clearly rejected, which implies that the US budget deficit would have been only weakly sustainable as in the whole sample. In turn, in the third regime (1982:1-1996:2) the null of deterministic cointegration is again not rejected at the $1 \%$ level, but now the estimate of $\beta$ would not be significantly different from one according to the Wald test, so that the US budget deficit would have been strongly sustainable during this period. Finally, in the fourth regime (1996:3-2005:3) no long-run relationship between public revenues and expenditures would appear, since the null of deterministic cointegration is now rejected at the $10 \%$ level, and with an estimate of $\beta$ well above one, reflecting the fact that the US budget deficit would have registered a large surplus during an important part of this period. The above results are summarized in Table 4. 


\section{Conclusions}

In this paper we have re-examined the long-run sustainability of US budget deficits, using the multiple structural change approach of Bai and Perron (1998, 2003a). We found evidence of weak sustainability of the deficit over the full sample 1947:1-2005:3, extending previous results obtained for the period ending at the early 1990s. In addition, we have detected up to three breaks (estimated at 1955:3,1982:1, and 1996:3) along the whole sample period, so that the US budget deficit would have been strongly sustainable only in the third regime (1982:1-1996:2), weakly sustainable in the first and second regimes (1947:11955:2 and 1955:3-1981:4, respectively), and a surplus would have prevailed over the final regime (1996:3-2005:3).

\section{References}

[1] Bai, J. and Perron, P. (1998): "Estimating and testing linear models with multiple structural changes", Econometrica, 66, 47-78.

[2] Bai, J. and Perron, P. (2003a): "Computation and analysis of multiple structural change models", Journal of Applied Econometrics, 18, 1-22.

[3] Bai, J. and Perron, P. (2003b): "Critical values for multiple structural change tests", Econometrics Journal, 6, 72-78.

[4] Bai, J. and Perron, P. (2006): "Multiple structural change models: A simulation analysis", in D. Corbae, S. N. Durlauf and B. E. Hansen (eds.): Econometric Theory and Practice: Frontiers of Analysis and Applied Research, Cambridge: Cambridge University Press, 212-238.

[5] Hamilton, J. D. and Flavin, M. A. (1986): "On the limitations of government borrowing: A framework for empirical testing", American Economic Review, 76, 808-819.

[6] Haug, A. A. (1991): "Cointegration and government borrowing constraints: Evidence for the United States", Journal of Business and Economic Statistics, 9, 97-101.

[7] Martin, G. (2000): "US deficit sustainability: A new approach based on multiple endogenous breaks", Journal of Applied Econometrics, 15, 83-105.

[8] Newey, W. K. and West, K. D. (1987): "A simple, positive semidefinite, heteroskedasticity and autocorrelation consistent covariance matrix", Econometrica, 55, 703-708.

[9] Ng, S. and Perron, P. (2001): "Lag length selection and the construction of unit root tests with good size and power", Econometrica, 69, 1529-1554. 
[10] Perron, P. and Ng, S. (1996): "Useful modifications to some unit root tests with dependent errors and their local asymptotic properties", Review of Economic Studies, 63, 435-463.

[11] Quintos, C. E. (1995): "Sustainability of the deficit process with structural shifts", Journal of Business and Economic Statistics, 13, 409-417.

[12] Shin, Y. (1994): "A residual-based test of the null of cointegration against the alternative of no cointegration", Econometric Theory, 10, 91-115.

[13] Stock, J. H. and Watson, M. W. (1993): "A simple estimator of cointegrating vectors in higher order integrated systems", Econometrica, 61, 783-820.

[14] Trehan, B. and Walsh, C. E. (1988): "Common trends, the government's budget balance, and revenue smoothing", Journal of Economic Dynamics and Control, 12, 425-444.

[15] Trehan, B. and Walsh, C. E. (1991): "Testing intertemporal budget constraints: Theory and applications to U.S. federal budget and current account deficits", Journal of Money, Credit, and Banking, 23, 206-223.

[16] Wilcox, D. W. (1989): "The sustainability of government deficits: Implications of the present-value borrowing constraint", Journal of Money, Credit, and Banking, 21, 291-306. 
Table 1

Ng-Perron tests of unit roots

\begin{tabular}{l|c|c|c}
\hline $\mathrm{I}(2)$ vs. I $(1)$ & \multicolumn{3}{|c}{ Case: $p=0, \bar{c}=-7.0$} \\
\hline Variable & $M Z_{\alpha}^{G L S}$ & $M Z_{t}^{G L S}$ & $A D F^{G L S}$ \\
\hline$\Delta R_{t}$ & $-42.30^{*}$ & $-4.58^{*}$ & $-6.03^{*}$ \\
$\Delta G_{t}$ & $-63.41^{*}$ & $-5.61^{*}$ & $-7.40^{*}$ \\
\hline \hline
\end{tabular}

\begin{tabular}{l|c|c|c}
\hline $\mathrm{I}(1)$ vs. $\mathrm{I}(0)$ & \multicolumn{3}{|c}{ Case: $p=1, \bar{c}=-13.5$} \\
\hline Variable & $M Z_{\alpha}^{G L S}$ & $M Z_{t}^{G L S}$ & $A D F^{G L S}$ \\
\hline$R_{t}$ & -1.54 & -0.77 & -0.78 \\
$G_{t}$ & 0.99 & 0.70 & 0.66 \\
\hline \hline
\end{tabular}

Notes:

$a *$ denotes significance at the $1 \%$ level. The critical values are taken from $\mathrm{Ng}$ and Perron (2001), Table 1.

${ }^{b}$ The autoregressive truncation lag has been selected using the modified Akaike information criterion, as proposed by Perron and Ng (1996). 
Table 2

Estimation of long-run relationships: Stock-Watson-Shin cointegration tests

\begin{tabular}{l|c|c|c|c|c}
\hline $\begin{array}{l}\text { Parameter } \\
\text { estimates }\end{array}$ & $\begin{array}{c}\text { Full sample } \\
1947: 1-2005: 3\end{array}$ & $\begin{array}{c}\text { First regime } \\
1947: 1-1955: 2\end{array}$ & $\begin{array}{c}\text { Second regime } \\
1955: 3-1981: 4\end{array}$ & $\begin{array}{c}\text { Third regime } \\
1982: 1-1996: 2\end{array}$ & $\begin{array}{c}\text { Fourth regime } \\
1996: 3-2005: 3\end{array}$ \\
\hline$\alpha$ & 0.36 & 0.99 & 0.31 & -0.65 & -26.5 \\
$\beta$ & $(2.42)$ & $(2.47)$ & $(2.14)$ & $(-0.59)$ & $(-3.48)$ \\
& 0.93 & 0.83 & 0.94 & 1.06 & 4.35 \\
& $(47.4)$ & $(12.76)$ & $(46.24)$ & $(7.59)$ & $(4.51)$ \\
\hline$R^{2}$ & 0.99 & 0.91 & 0.99 & 0.97 & 0.98 \\
$\hat{\sigma}^{2}$ & 0.045 & 0.056 & 0.035 & 0.026 & 0.013 \\
$C_{\mu}$ & 0.087 & 0.079 & 0.061 & 0.093 & $0.310^{* * *}$ \\
$W_{D O L S}$ & $10.15^{*}$ & $6.62^{*}$ & $6.22^{* *}$ & 0.24 & $12.08^{*}$ \\
\hline \hline
\end{tabular}

\section{Notes:}

$a *, * *$, and $* * *$ denote significance at the $1 \%, 5 \%$, and $10 \%$ levels, respectively. The critical values for the Shin test are taken from Shin (1994), Table 1, for $m=1$.

${ }^{b} t$-statistics in parentheses.

c The number of leads and lags selected was $q=3 \simeq \operatorname{INT}\left(T^{1 / 3}\right)$, as proposed in Stock and Watson (1993). The long-run variance of the cointegrating regression residuals was estimated using the Bartlett window with $l=5 \simeq I N T\left(T^{1 / 2}\right)$, as proposed in Newey and West (1987). 
Table 3

Bai-Perron tests of multiple structural changes in the long-run relationship

Tests statistics:

\begin{tabular}{c|c|c|c|c}
\hline$U D \max$ & $W D \max$ & & & \\
$138.67^{*}$ & $136.45^{*}$ & & & \\
\hline $\sup F_{T}(1)$ & $\sup F_{T}(2)$ & $\sup F_{T}(3)$ & $\sup F_{T}(4)$ & $\sup F_{T}(5)$ \\
$136.45^{*}$ & $92.41^{*}$ & $92.66^{*}$ & $70.48^{*}$ & $57.63^{*}$ \\
\hline $\sup F_{T}(2 \mid 1)$ & $\sup F_{T}(3 \mid 2)$ & $\sup F_{T}(4 \mid 3)$ & $\sup F_{T}(5 \mid 4)$ & \\
$38.27^{*}$ & $64.22^{*}$ & 4.76 & 0.0 & \\
\hline \hline
\end{tabular}

Break dates estimates:

\begin{tabular}{c|c}
\hline$T_{1}$ & $1955: 3$ \\
& {$[1955: 1-1957: 3]$} \\
$T_{2}$ & $1982: 1$ \\
& {$[1980: 4-1982: 2]$} \\
$T_{3}$ & $1996: 3$ \\
& {$[1996: 2-1996: 4]$} \\
\hline \hline
\end{tabular}

Notes:

$a *$ denotes significance at the $1 \%$ level. The critical values are taken from Bai and Perron (1998), tables I and II; and from Bai and Perron (2003b), tables 1 and 2.

${ }^{b}$ The number of breaks (in our case, three) has been determined according to the sequential procedure of Bai and Perron (1998), at the $5 \%$ size for the sequential test $\sup F_{T}(l+1 \mid l)$.

${ }^{c} 95 \%$ confidence intervals in brackets. 
Table 4

Sustainability of the US public deficit: Summary results

\begin{tabular}{l|c|c|c|c|c}
\hline & Full sample & First regime & Second regime & Third regime & Fourth regime \\
& $1947: 1-2005: 3$ & $1947: 1-1955: 2$ & $1955: 3-1981: 4$ & $1982: 1-1996: 2$ & $1996: 3-2005: 3$ \\
\hline Cointegration & Yes & Yes & Yes & Yes & No \\
Estimate of $\beta$ & 0.93 & 0.83 & 0.94 & 1.06 & 4.35 \\
Null $\hat{\beta}=1$ & No & No & No & Yes & No \\
Sustainability & Yes (weak) & Yes (weak) & Yes (weak) & Yes (strong) & - \\
\hline \hline
\end{tabular}




\title{
US deficit sustainability revisited: A multiple structural change approach*
}

\author{
Oscar Bajo-Rubio \\ Universidad de Castilla-La Mancha \\ and Instituto de Estudios Fiscales \\ Carmen Díaz-Roldán \\ Universidad de Castilla-La Mancha \\ Vicente Esteve \\ Universidad de Valencia
}

May 2006

\begin{abstract}
In this paper we re-examine the long-run sustainability of US budget deficits, using Bai and Perron's multiple structural change approach. While the deficit would have been weakly sustainable over the full sample (1947:1-2005:3), strong sustainability would appear only between 1982:1 and 1996:2.

Keywords: Fiscal policy; Sustainability; US budget deficit.

JEL classification: E62, H62.
\end{abstract}

\footnotetext{
*The authors acknowledge financial support from the regional government of Castilla-La Mancha, through the project PBI-05-008; and from the Spanish Ministry of Education and Science, through the projects SEJ2005-08738-C02-01 (O. Bajo-Rubio and C. Díaz-Roldán) and SEJ2005-01163 (V. Esteve).
} 


\section{Introduction}

US government finances have experienced a remarkable turnaround in recent years. Large budget deficits in the 1980s and early 1990s led to a substantial amount of empirical work aimed to examining their long-run sustainability. However, later on, the record surpluses in the late 1990s and early 2000s turned into record deficits after 2002, with budget projections showing large federal deficits over the next decade. As a result, the US general government deficit is now among the highest in the OECD, and its sustainability has become again a highly relevant issue.

When analyzing the sustainability of budget deficits, the traditional approach has consisted of testing whether the government's intertemporal budget constraint (IBC) holds, that is, whether the current market value of debt equals the discounted sum of expected future surpluses. However, empirical tests on sustainability are largely inconclusive due to differences in the econometric methodology, the particular specification of the transversality condition, and the sample period used.

Several procedures to test for the IBC have been proposed in the literature, focusing either on the univariate properties of the government's deficit and debt (e.g., Hamilton and Flavin, 1986; Wilcox, 1989), or on the presence of a long-run cointegration relationship between government revenues and expenditures (e.g., Trehan and Walsh, 1988, 1991; Haug, 1991). Furthermore, the eventual occurrence of a structural break in the cointegrating relationship has been examined in, e.g., Quintos (1995) and Martin (2000). Overall, the results of these and other studies suggest that the US deficit would have undergone a shift in recent times, with the deficit being either unsustainable or only weakly sustainable in the post-break period.

In this paper we re-examine the sustainability of US budget deficits, using a new approach developed by Bai and Perron $(1998,2003 a)$. This procedure allows to test endogenously for the presence of multiple structural changes in an estimated relationship, and has a number of advantages over previous approaches. In particular, the underlying assumptions are less restrictive, confidence intervals for the break dates can be calculated, the data and errors are allowed to follow different distributions across segments, and the sequential method used in the application can allow for the presence of serial correlation in the errors and heterogeneous variances across segments; see Bai and Perron (2006) for details. As a further contribution, as compared with previous studies where the sample ends at the early 1990s, our period of analysis extends to 2005, including the most recent developments in the evolution of the US budget deficit.

The rest of the paper is organized as follows. A brief description of the underlying theoretical framework is provided in section 2, the methodology and empirical results are presented in section 3 , and the main conclusions are summarized in section 4 . 


\section{Theoretical framework}

Assuming that budget deficits are financed using bonds of one-period maturity, in any single period a government faces the following budget constraint:

$$
\Delta B_{t}=G_{t}-R_{t}
$$

where $B_{t}, G_{t}$, and $R_{t}$ denote, respectively, the real market value of government debt, real government expenditure inclusive of interest payments, and real tax revenues. The real interest rate is assumed to be stationary around a mean $r$ so that, defining $E X P_{t}$ as $G_{t}-r B_{t-1}$, the constraint (1) can be rewritten as:

$$
B_{t}=E X P_{t}-R_{t}+(1+r) B_{t-1}
$$

Since (2) holds every period, solving for $B_{t}$ and iterating forward over an infinite horizon yields the IBC:

$$
B_{t}=\sum_{j=0}^{\infty}\left(\frac{1}{1+r}\right)^{j+1}\left(R_{t+j+1}-E X P_{t+j+1}\right)+\lim _{j \rightarrow \infty}\left(\frac{1}{1+r}\right)^{j+1} B_{t+j+1}
$$

If we denote as $E_{t}$ the expectations operator, conditional on information at time $t$, fiscal sustainability involves:

$$
\lim _{j \rightarrow \infty}\left(\frac{1}{1+r}\right)^{j+1} E_{t} B_{t+j+1}=0
$$

i.e., the government must run future budget surpluses equal, in present-value terms, to the current value of its outstanding debt; in other words, the budget deficit would be sustainable if and only if the stock of debt is expected to grow no faster on average than $r$ (taken as a proxy of the growth rate of the economy).

The cointegration framework for testing the IBC would follow once first differences are taken in (3):

$\Delta B_{t}=\sum_{j=0}^{\infty}\left(\frac{1}{1+r}\right)^{j+1}\left(\Delta R_{t+j+1}-\Delta E X P_{t+j+1}\right)+\lim _{j \rightarrow \infty}\left(\frac{1}{1+r}\right)^{j+1} \Delta B_{t+j+1}$

so that sustainability would require:

$$
\lim _{j \rightarrow \infty}\left(\frac{1}{1+r}\right)^{j+1} E_{t} \Delta B_{t+j+1}=0
$$

Under a no-Ponzi scheme rule, the right-hand side of equation (5) will be stationary as long as government revenues and expenditures, and the stock of public debt, are all stationary in first differences. In order to test for condition (6), the usual procedure consists of testing for the stationarity of $\Delta B_{t}=G_{t}-R_{t}$, 
provided that both $G_{t}$ and $R_{t}$ are I(1), with a cointegration relationship $(1,-1)$, in a regression model of the form:

$$
R_{t}=\alpha+\beta G_{t}+\varepsilon_{t}
$$

and then testing the linear restriction $\beta=1$. In particular, Quintos (1995) shows that:

(i) The fiscal deficit would be strongly sustainable if and only if $R_{t}$ and $G_{t}$ are cointegrated and $\beta=1$.

(ii) The fiscal deficit would be only weakly sustainable if $R_{t}$ and $G_{t}$ are cointegrated and $0<\beta<1$.

(iii) The fiscal deficit would be unsustainable if $\beta \leq 0$.

\section{Methodology and empirical results}

In this section we provide a test of the sustainability of the US budget deficit, over the period 1947:1 to 2005:3 ${ }^{1}$. The data on federal government revenues and expenditures, inclusive of interest paid on debt, are taken from the National Income Product Accounts (NIPA, Table 3.1), and real values are calculated using the GDP deflator (NIPA, Table 1.1.4).

As a first step of the analysis, we test for the order of integration of the series using the tests of $\mathrm{Ng}$ and Perron (2001). The results are shown in Table 1 , and the null hypothesis of non stationarity cannot be rejected, independently of the test, for the two series in levels; at the same time that the presence of two unit roots is clearly rejected at the $1 \%$ significance level. Accordingly, both series would be concluded to be I(1).

Next, we perform a cointegration analysis of equation (7) over the whole sample, with no breaks included. The estimation is made using the method of Dynamic Ordinary Least Squares (DOLS) of Stock and Watson (1993). So, we first estimate a long-run dynamic equation including leads and lags of the explanatory variables in equation (7):

$$
R_{t}=\alpha+\beta G_{t}+\sum_{j=-q}^{q} \gamma_{j} \Delta G_{t-j}+v_{t}
$$

where $v_{t}$ is an error term, and then perform Shin's (1994) test from the calculation of $C_{\mu}$, a LM statistic from the DOLS residuals, which tests for deterministic cointegration (i.e., when no trend is present in the regression).

The results in the first column of Table 2 show that the null of deterministic cointegration between $R_{t}$ and $G_{t}$ is not rejected at the $1 \%$ level of significance,

\footnotetext{
${ }^{1}$ An alternative, though indirect, way of analyzing the sustainability of fiscal policy (used, e.g., in the context of testing for the fiscal theory of the price level) involves the estimation of a long-run (cointegration) relationship between budget surplus and (lagged) government debt, so that a positive and significant estimate of the regression coefficient would be a sufficient condition for solvency. Then, when a government is solvent (i.e., satisfies the IBC), its fiscal policy is sustainable; this is the approach followed in, e.g., Bohn (1998), Tanner and Ramos (2003), or Bajo-Rubio, Díaz-Roldán and Esteve (2006).
} 
and the estimated value for $\beta$ is 0.93 , significantly different from zero at the $1 \%$ level. But this estimate would be significantly different from one at the $1 \%$ level, according to a Wald test on the null hypothesis $\hat{\beta}=1$ against the alternative $\hat{\beta}<1$, distributed as a $\chi_{1}^{2}$ and denoted by $W_{D O L S}$ in Table 2. Accordingly, since $R_{t}$ and $G_{t}$ would be cointegrated and $0<\hat{\beta}<1$, the US fiscal deficit would have been only weakly sustainable over the full sample 1947:1-2005:3. This would confirm, over a more extended period, previous results by Quintos (1995) and Martin (2000) for the same sample ending at 1992.3.

But the main objective of this section is estimating equation (7) through a multiple endogenous break model. Hence, we now proceed to test for multiple breaks at unknown dates in equation (7), making use of the approach of Bai and Perron (1998, 2003a), who suggest several statistics in order to identify the break points:

- The $\sup F_{T}(k)$ test, i.e., a sup $F$-type test of the null hypothesis of no structural break versus the alternative of a fixed (arbitrary) number of breaks $k$.

- Two maximum tests of the null hypothesis of no structural break versus the alternative of an unknown number of breaks given some upper bound, i.e., $U D \max$ test, an equal weighted version, and $W D \max$ test, with weights that depend on the number of regressors and the significance level of the test.

- The $\sup F_{T}(l+1 \mid l)$ test, i.e., a sequential test of the null hypothesis of $l$ breaks versus the alternative of $l+1$ breaks.

The results of applying the Bai-Perron tests to the relationship between $R_{t}$ and $G_{t}$, allowing up to five breaks, are shown in Table 3 . Both the $U D$ max and $W D$ max tests are highly significant, which implies that at least one break is present. Next, all the $\sup F_{T}(k)$ tests are significant, with $k$ running between 1 and 5 , so that at least one break would be present in this relationship. In turn, the $\sup F_{T}(l+1 \mid l)$ test is not significant for any $l \geq 3$, so the sequential procedure selects three breaks. Hence, the results of the Bai-Perron tests would suggest a model of four regimes, with the dates of the breaks estimated at 1955:3, 1982:1, and 1996:3; their confidence intervals are shown in Table 3.

Finally, we proceed to estimate the cointegration equation (8) for the four sub-samples, and the results are shown in the last four columns of Table 2. As can be seen, in the first and second regimes (1947:1-1955:2 and 1955:3-1981:4) the null of deterministic cointegration is not rejected at the $1 \%$ level, and the restriction on the estimate of $\beta$ being equal to one is clearly rejected, which implies that the US budget deficit would have been only weakly sustainable as in the whole sample. In turn, in the third regime (1982:1-1996:2) the null of deterministic cointegration is again not rejected at the $1 \%$ level, but now the estimate of $\beta$ would not be significantly different from one according to the Wald test, so that the US budget deficit would have been strongly sustainable during this period. However, in the fourth regime (1996:3-2005:3) no long-run 
relationship between public revenues and expenditures would appear, since the null of deterministic cointegration is now rejected at the $10 \%$ level, and the estimate of $\beta$ would be above one; hence, no clear conclusions can be drawn for this period, characterized by decreasing deficits at the start, which became surpluses from 1998:1 on (and reached record figures in 2000), followed again by large deficits after 2001:3. The above results are summarized in Table 4.

\section{Conclusions}

In this paper we have re-examined the long-run sustainability of US budget deficits, using the multiple structural change approach of Bai and Perron (1998, 2003a). We found evidence of weak sustainability of the deficit over the full sample 1947:1-2005:3, extending previous results obtained for the period ending at the early 1990s. In addition, we have detected up to three breaks (estimated at 1955:3, 1982:1, and 1996:3) along the whole sample period, so that the US budget deficit would have been strongly sustainable only in the third regime (1982:1-1996:2), weakly sustainable in the first and second regimes (1947:11955:2 and 1955:3-1981:4, respectively), and no clear conclusions emerge for the final regime (1996:3-2005:3), where both record surpluses and large deficits would have coexisted.

\section{References}

[1] Bai, J. and Perron, P. (1998): "Estimating and testing linear models with multiple structural changes", Econometrica, 66, 47-78.

[2] Bai, J. and Perron, P. (2003a): "Computation and analysis of multiple structural change models", Journal of Applied Econometrics, 18, 1-22.

[3] Bai, J. and Perron, P. (2003b): "Critical values for multiple structural change tests", Econometrics Journal, 6, 72-78.

[4] Bai, J. and Perron, P. (2006): "Multiple structural change models: A simulation analysis", in D. Corbae, S. N. Durlauf and B. E. Hansen (eds.): Econometric Theory and Practice: Frontiers of Analysis and Applied Research, Cambridge: Cambridge University Press, 212-238.

[5] Bajo-Rubio, O., Díaz-Roldán, C. and Esteve, V. (2006): "Deficit sustainability and inflation in EMU: An analysis from the fiscal theory of the price level", Working Paper, Instituto de Estudios Fiscales, forthcoming.

[6] Bohn, H. (1998): "The behavior of U.S. public debt and deficits", Quarterly Journal of Economics, 113, 949-963.

[7] Hamilton, J. D. and Flavin, M. A. (1986): "On the limitations of government borrowing: A framework for empirical testing", American Economic Review, 76, 808-819. 
[8] Haug, A. A. (1991): "Cointegration and government borrowing constraints: Evidence for the United States", Journal of Business and Economic Statistics, 9, 97-101.

[9] Martin, G. (2000): "US deficit sustainability: A new approach based on multiple endogenous breaks", Journal of Applied Econometrics, 15, 83-105.

[10] Newey, W. K. and West, K. D. (1987): "A simple, positive semidefinite, heteroskedasticity and autocorrelation consistent covariance matrix", Econometrica, 55, 703-708.

[11] Ng, S. and Perron, P. (2001): "Lag length selection and the construction of unit root tests with good size and power", Econometrica, 69, 1529-1554.

[12] Perron, P. and Ng, S. (1996): "Useful modifications to some unit root tests with dependent errors and their local asymptotic properties", Review of Economic Studies, 63, 435-463.

[13] Quintos, C. E. (1995): "Sustainability of the deficit process with structural shifts", Journal of Business and Economic Statistics, 13, 409-417.

[14] Shin, Y. (1994): "A residual-based test of the null of cointegration against the alternative of no cointegration", Econometric Theory, 10, 91-115.

[15] Stock, J. H. and Watson, M. W. (1993): "A simple estimator of cointegrating vectors in higher order integrated systems", Econometrica, 61, 783-820.

[16] Tanner, E. and Ramos, A. M. (2003): "Fiscal sustainability and monetary versus fiscal dominance: Evidence from Brazil, 1991-2000", Applied Economics, 35, 859-873.

[17] Trehan, B. and Walsh, C. E. (1988): "Common trends, the government's budget balance, and revenue smoothing", Journal of Economic Dynamics and Control, 12, 425-444.

[18] Trehan, B. and Walsh, C. E. (1991): "Testing intertemporal budget constraints: Theory and applications to U.S. federal budget and current account deficits", Journal of Money, Credit, and Banking, 23, 206-223.

[19] Wilcox, D. W. (1989): "The sustainability of government deficits: Implications of the present-value borrowing constraint", Journal of Money, Credit, and Banking, 21, 291-306. 
Table 1

Ng-Perron tests of unit roots

\begin{tabular}{l|c|c|c}
\hline $\mathrm{I}(2)$ vs. I $(1)$ & \multicolumn{3}{|c}{ Case: $p=0, \bar{c}=-7.0$} \\
\hline Variable & $M Z_{\alpha}^{G L S}$ & $M Z_{t}^{G L S}$ & $A D F^{G L S}$ \\
\hline$\Delta R_{t}$ & $-42.30^{*}$ & $-4.58^{*}$ & $-6.03^{*}$ \\
$\Delta G_{t}$ & $-63.41^{*}$ & $-5.61^{*}$ & $-7.40^{*}$ \\
\hline \hline
\end{tabular}

\begin{tabular}{l|c|c|c}
\hline $\mathrm{I}(1)$ vs. I $(0)$ & \multicolumn{3}{|c}{ Case: $p=1, \bar{c}=-13.5$} \\
\hline Variable & $M Z_{\alpha}^{G L S}$ & $M Z_{t}^{G L S}$ & $A D F^{G L S}$ \\
\hline$R_{t}$ & -1.54 & -0.77 & -0.78 \\
$G_{t}$ & 0.99 & 0.70 & 0.66 \\
\hline \hline
\end{tabular}

Notes:

$a *$ denotes significance at the $1 \%$ level. The critical values are taken from Ng and Perron (2001), Table 1.

${ }^{b}$ The autoregressive truncation lag has been selected using the modified Akaike information criterion, as proposed by Perron and Ng (1996). 
Table 2

Estimation of long-run relationships: Stock-Watson-Shin cointegration tests

\begin{tabular}{l|c|c|c|c|c}
\hline $\begin{array}{l}\text { Parameter } \\
\text { estimates }\end{array}$ & $\begin{array}{c}\text { Full sample } \\
1947: 1-2005: 3\end{array}$ & $\begin{array}{c}\text { First regime } \\
1947: 1-1955: 2\end{array}$ & $\begin{array}{c}\text { Second regime } \\
1955: 3-1981: 4\end{array}$ & $\begin{array}{c}\text { Third regime } \\
1982: 1-1996: 2\end{array}$ & $\begin{array}{c}\text { Fourth regime } \\
1996: 3-2005: 3\end{array}$ \\
\hline$\alpha$ & 0.36 & 0.99 & 0.31 & -0.65 & -26.5 \\
$\beta$ & $(2.42)$ & $(2.47)$ & $(2.14)$ & $(-0.59)$ & $(-3.48)$ \\
& 0.93 & 0.83 & 0.94 & 1.06 & 4.35 \\
& $(47.4)$ & $(12.76)$ & $(46.24)$ & $(7.59)$ & $(4.51)$ \\
\hline$R^{2}$ & 0.99 & 0.91 & 0.99 & 0.97 & 0.98 \\
$\hat{\sigma}^{2}$ & 0.045 & 0.056 & 0.035 & 0.026 & 0.013 \\
$C_{\mu}$ & 0.087 & 0.079 & 0.061 & 0.093 & $0.310^{* * *}$ \\
$W_{D O L S}$ & $10.15^{*}$ & $6.62^{*}$ & $6.22^{* *}$ & 0.24 & $12.08^{*}$ \\
\hline \hline
\end{tabular}

Notes:

$a *, * *$, and $* * *$ denote significance at the $1 \%, 5 \%$, and $10 \%$ levels, respectively. The critical values for the Shin test are taken from Shin (1994), Table 1, for $m=1$.

${ }^{b} t$-statistics in parentheses.

c The number of leads and lags selected was $q=3 \simeq \operatorname{INT}\left(T^{1 / 3}\right)$, as proposed in Stock and Watson (1993). The long-run variance of the cointegrating regression residuals was estimated using the Bartlett window with $l=5 \simeq I N T\left(T^{1 / 2}\right)$, as proposed in Newey and West (1987). 
Table 3

Bai-Perron tests of multiple structural changes in the long-run relationship

Tests statistics:

\begin{tabular}{c|c|c|c|c}
\hline$U D \max$ & $W D \max$ & & & \\
$138.67^{*}$ & $136.45^{*}$ & & & \\
\hline $\sup F_{T}(1)$ & $\sup F_{T}(2)$ & $\sup F_{T}(3)$ & $\sup F_{T}(4)$ & $\sup F_{T}(5)$ \\
$136.45^{*}$ & $92.41^{*}$ & $92.66^{*}$ & $70.48^{*}$ & $57.63^{*}$ \\
\hline $\sup F_{T}(2 \mid 1)$ & $\sup F_{T}(3 \mid 2)$ & $\sup F_{T}(4 \mid 3)$ & $\sup F_{T}(5 \mid 4)$ & \\
$38.27^{*}$ & $64.22^{*}$ & 4.76 & 0.0 & \\
\hline \hline
\end{tabular}

Break dates estimates:

\begin{tabular}{c|c}
\hline$T_{1}$ & $1955: 3$ \\
& {$[1955: 1-1957: 3]$} \\
$T_{2}$ & $1982: 1$ \\
& {$[1980: 4-1982: 2]$} \\
$T_{3}$ & $1996: 3$ \\
& {$[1996: 2-1996: 4]$} \\
\hline \hline
\end{tabular}

Notes:

$a *$ denotes significance at the $1 \%$ level. The critical values are taken from Bai and Perron (1998), tables I and II; and from Bai and Perron (2003b), tables 1 and 2.

${ }^{b}$ The number of breaks (in our case, three) has been determined according to the sequential procedure of Bai and Perron (1998), at the 5\% size for the sequential test $\sup F_{T}(l+1 \mid l)$.

${ }^{c} 95 \%$ confidence intervals in brackets. 
Table 4

Sustainability of the US public deficit: Summary results

\begin{tabular}{l|c|c|c|c|c}
\hline & Full sample & First regime & Second regime & Third regime & Fourth regime \\
& $1947: 1-2005: 3$ & $1947: 1-1955: 2$ & $1955: 3-1981: 4$ & $1982: 1-1996: 2$ & $1996: 3-2005: 3$ \\
\hline Cointegration & Yes & Yes & Yes & Yes & No \\
Estimate of $\beta$ & 0.93 & 0.83 & 0.94 & 1.06 & 4.35 \\
Null $\hat{\beta}=1$ & No & No & No & Yes & No \\
Sustainability & Yes (weak) & Yes (weak) & Yes (weak) & Yes (strong) & - \\
\hline \hline
\end{tabular}

